\title{
Effects of four generations of density-dependent selection on life history traits and their plasticity in a clonally propagated plant
}

\author{
M. VAN KLEUNEN \& M. FISCHER \\ Institut fïr Umwellwissenschaften, Universität Zürich, Winterthurerstrasse 190, CH-8057 Zïrich, Switzerland
}

\author{
Keywords: \\ adaptation; \\ clonal growth; \\ genetic variation; \\ guerrilla; \\ phalanx; \\ phenotypic plasticity; \\ Ranunculus reptans; \\ reproductive allocation; \\ selection.
}

\begin{abstract}
Life history evolution of many clonal plants takes place with long periods of exclusively clonal reproduction and under largely varying ramet densities resulting from clonal reproduction. We asked whether life history traits of the clonal herb Ranunculus reptans respond to density-dependent selection, and whether plasticity in these traits is adaptive. After four generations of exclusively clonal propagation of 16 low and 16 high ramet-density lines, we studied life history traits and their plasticities at two test ramet-densities. Plastic responses to higher test-density consisted of a shift from sexual to vegetative reproduction, and reduced flower production, plant size, branching frequency, and lengths of leaves and internodes. Plants of high-density lines tended to have longer leaves, and under high test-density branched less frequently than those of low-density lines. Directions of these selection responses indicate that the observed plastic branching response is adaptive, whereas the plastic leaf length response is not. The reverse branching frequency pattern at low test-density, where plants of high-density lines branched more frequently than those of low-density lines, indicates evolution of plasticity in branching. Moreover, when grown under less stressful low testdensity, plants of high-density lines tended to grow larger than the ones of low-density lines. We conclude that ramet density allects clonal life-history evolution and that under exclusively clonal propagation clonal life-history traits and their plasticities evolve differently at different ramet densities.
\end{abstract}

\section{Introduction}

As modular organisms, many plant species can reproduce clonally (Salisbury, 1942; Klimeš et al., 1997). Many clonal plants experience long periods of exclusively clonal reproduction, and some populations of clonal plants even have lost the potential to reproduce sexually (Eckert, 2001). During periods of exclusively clonal reproduction, selection may act on clonal life history traits if it causes higher rates of survival or clonal reproduction of genets with some traits than of genets with other traits, i.e. if so-called sorting out takes place in this intergenotype selection (Solbrig \& Simpson, 1977).

Correspondence: Mark van Kleumen, Departmemt of Forest Science, The University of British Columbia. 2424 Main Mall Vancouver, BC V6TIZ4 Canada.

Tcl.: 001604822 5841: [ax: 0016048229102 :

c-mail: vklcuncnœuwinsl.unizh.h.ch
Density is an important ecological lactor for most organisms because it affects resource availability and interactions with other organisms such as herbivores and pollinators. As a consequence, density-dependent selection or the closely related concept of $r$ - and K-selection (MacArthur \& Wilson, 1967) are considered very important in life history evolution. As a consequence of clonal reproduction, ramet densities can vary largely within and among populations of clonal plants. However. empirical tests of responses to density-dependent selection have been limited to a few model species, mainly insects and bacteria (Mueller, 1997), whereas such tests are scarce for plants. Moreover, most of these studies, with the exception of the ones on bacteria, involve species which exclusively reproduce sexually.

As a further consequence of clonal reproduction, clonal plants have particular life-history characteristics, such as the relative allocation to sexual and vegetative reproduction, and the growth form of genets (Fischer 
G van Kleunen, 2001). Because clonal plants may grow short or long spacers and branch less or more frequently, their growth form may range from a compact one with highly aggregated ramets to a spreading one with more dispersed ramets (i.e. so-called phalanx and guerrilla strategy, respectively; Lovett Doust, 1981). Moreover, plasticity in growth form may allow for selective placement of ramets in more favourable microsites (i.e. so-called foraging; Harper, 1981; Bell, 1984). Different clonal life history traits may be of advantage at different levels of intraspecific competition (Sackville Hamilton et al., 1987; van Kleunen et al., 2001). A guerrilla growth form allows rapid occupation of the available space under low density, whereas the competitively stronger phalanx growth form may be more beneficial under high density (Winkler 6. Schmid, 1995; Winkler et al., 1999). On the other hand, a guerrilla growth form may allow a plant to escape from unfavourable high local density, whereas a phalanx growth form may allow a plant to remain in beneficial low local density.

Clonal plants may respond to increased intraspecific competition under increased ramet density by plastic changes in their life-history traits (Schmid \& Harper, 1985; Humphrey \& Pyke, 1998; van Kleunen et al., 2001). Under high ramet density, a high allocation to sexual reproduction may allow escape from locally adverse conditions through seed dispersal (Ogden, 1974; Abrahamson, 1975; Loehle, 1987), whereas on the other hand a high allocation to vegetative reproduction, may be beneficial to increase competitive strength through increased size (Loehle, 1987). So, predictions on the direction of plastic responses of clonal life history traits to density are not equivocal.

Although plastic responses may be adaptive, this is not necessarily the case (Sultan, 1992). Many plastic responses may just represent passive growth responses as a consequence of resource limitation in one of the environments (Leeflang et al., 1998; van Kleunen et al., 2000a). When a plastic increase or decrease in a trait in response to density is adaptive (i.e. increases fitness) rather than passive, density should accordingly select for high or low trait values, respectively (Scheiner $\delta$ Callahan, 1999; Schmitt et al., 1999). This means that the direction of the response to selection may indicate whether a plastic response is adaptive. Density may thus not only induce plastic changes in life history traits but also result in local adaptation through evolutionary change in mean trait values (MacArthur \& Wilson, 1967; Pianka, 1970; Sackville Hamilton et al., 1987). Moreover, plasticity may be heritable itself and therefore respond to selection (Bradshaw, 1965; Van Buskirk \& Relyea, 1998; Lively, 1999; Weinig, 2000; Donohue et al., 2001).

In a previous study on plastic responses of the stoloniferous herb Ranunculus reptans to density, we found that under high density, the allocation to sexual reproduction was larger than under low density (van
Kleunen et al., 2001). If this constitutes an adaptive phenotypic response to density, genotypes with a high allocation to sexual reproduction should be selectively lavoured under high density. Reproductive allocation and the growth form of $R$, reptans have the potential 10 evolve as indicated by significant responses to artificial selection on the proportion of flowering rosettes and on growth form (van Kleunen et al., 2002; M. Fischer, $M$. van Kleunen \& B. Schmid, unpublished results). Moreover, density is likely to be an important selective force in natural populations of $R$. reptans because it grows in varying densities on periodically inundated lake shores with low vegetation cover (Prati \& Peintinger, 2000). Further, intergenotype selection may be important for evolution in this species because sexual reproduction or seedling establishment are precluded in some years because of unpredictable water level fluctuations (Prati \& Peintinger, 2000).

Starting from a base population founded from 40 genotypes of $R$. reptans, we started 16 low- and 16 highdensity lines. After four cycles of random selection of rooted rosettes (i.e. of exclusively clonally propagated offspring) under low and high density, we planted the fourth clonal offspring generation of each line at both low and high test-density. We asked the following specific questions: (1) Do reproductive allocation, growth form and fitness characteristics of $R$. reptans respond plastically to ramet density? (2) Do plants of low- and high-density lines of $R$. reptans differ in reproductive allocation, growth form and fitness characteristics, and in their plasticities? (3) Do plastic responses to density and responses to density-dependent sclection point into the same direction, i.e. are the plastic responses adaptive?

\section{Materials and methods}

\section{Study species}

The stolonilerous, rosette-forming herb Ranunculus reptans L. (Ranunculaceae) has a circumpolar distribution, mainly in the temperate to boreal-subarctic zones of Europe, Asia and North America (Hess et al., 1980). The species has a strict habitat requirement and in Central Europe only grows on periodically inundated lake shores with very low vegetation cover. Because of the regulation of water levels of most lakes, $R$. reptans has become a rare species in Central Europe where it is now restricted to a few lakes in the foothill zone of the Alps. Today most populations in Central Europe are found around Lake Constance on the borders of Austria, Germany and Switzerland.

Rosettes (i.e. ramets) of $R$. reptans may grow up to 20 leaves. Leaf blades are $10-50 \mathrm{~mm}$ long and $1-5 \mathrm{~mm}$ wide and gradually narrow into the petioles. Rosettes form stolon branches from axillary meristems. Stolons consist of rosettes connected by thin (0.5-2.0 mm diameter) internodes with a length of $3-5 \mathrm{~cm}$. Siolon branches can 
grow 10-20 cm within one growing season, which may result in high rosette densities. Each stolon node (i.e. rosette) has the potential to produce roots and one single flower, which develops already before the actual leat rosette is formed. As a consequence, vegetative and sexual reproduction are not mutually exclusive in $R$. reptans. The slightly protandrous flowers of the partly selfincompatible $R$. reptans can produce 10-20 seeds (Prati 6 Peintinger, 2000). Growth slows down during the summer-inundation period, and plants overwinter as small, short-leaved rosettes (Prati \& Peintinger, 2000).

\section{Collection and precultivation of plants}

To comprehensively sample potential genetic variation of $R$. reptans, we collected a total of 40 plants from 10 sites around Lake Constance from 1995 to 1997. These 40 plants therefore represent the meta-population of $R$. reptans at Lake Constance. RAPD-analysis revealed that all 40 plants represented different genotypes (Fischer et al., 2000b). Moreover, we found significant variation among these genotypes in the proportion of flowering and rooted rosettes, leaf and internode length and spatial spread per rosette when they were grown in a competition-free environment (for each trait $\mathrm{P}<0.05$; $\mathrm{M}$. van Kleunen, unpublished results). The collected plants were propagated repeatedly, and vegetative of [spring were kept in $40 \times 70 \mathrm{~cm}$ trays filled with a $4: 1$ mixture of sand and compost. On 8 August 1997, we founded 32 artificial populations each with plants from all 40 genotypes in 32 trays with a dimension of $31 \times 44 \mathrm{~cm}$, filled with a $4: 1$ mixture of sand and compost. Both the precultivation of plants and the experiment described below took place in a plant room at $25^{\circ} \mathrm{C}$ with $16 \mathrm{~h}$ of artificial light of a photon flux density of $c .300 \mu \mathrm{mol} \mathrm{m} \mathrm{m}^{-2} \mathrm{~s}^{-1}$.

\section{Experimental set-up}

On 5 March 1998, we excavated all rooted rosettes from the 32 trays, removed their stolon branches, and pooled the rosettes. Then we assigned randomly chosen individual rosettes to evenly spaced, hexagonally arranged planting positions in each of the 32 trays with a dimension of $31 \times 44 \mathrm{~cm}$ filled with a soil mixture of the same composition as described above. The soil was covered with a thin layer of gravel to prevent the growth of algae and to reduce evaporation. To start 16 low- and 16 high-density lines, we planted into half of the trays 40 rosettes (293 rosettes $\mathrm{m}^{-2}$ ) and into the other trays 200 rosettes ( 1466 rosettes $\mathrm{m}^{-2}$ ), respectively. Both densities are within the range of rosette densities observed in the field (M. Fischer, personal observation). Plants were watered at 2-day intervals, and trays were randomly assigned to new positions in the plant room at 2 -week intervals.

On 21 September 1998, we excavated all rooted rosettes from each tray (line) and removed their stolon branches. To start the first vegetative offspring generation of each low- and high-density line, we randomly chose 40 and 200 rosettes, respectively, and planted them in experimental trays similar to the ones used in the base generation. We repeated this selection procedure of vegetative offspring three more times. The last time, however, we randomly chose from each low- and highdensity line 120 rosettes, and grew them all at intermediate density for 63 days to reduce differences in maternal environmental carry-over effects between plants of low- and high-density lines. At the end of this precultivation, there were no significant differences in the size of rosettes between low- and high-density lines (number of leaves $x$ length of longest leaf $\pm S E$ was $352.2 \pm 15.0$ and $340.3 \pm 10.6 \mathrm{~mm}$ for the lowand high-density lines, respectively; $F_{1,29}=0.407$, $\mathrm{P}=0.529$ ). On 17 January 2000 , we excavated the 120 originally planted rosettes of each line, and planted 100 of them at high density and 20 at low density in test trays of half the size of the ones used in the previous generations. In this way, test densities were the same as earlier selection densities. During the experiment, two of the 64 test trays dried out.

\section{Measurements}

We measured changes in rosette density during the target generation (i.e. fourth vegetative offspring generation) by counting the number of rosettes and rooted rosettes in a $12.5 \times 18.0 \mathrm{~cm}$ area in the middle of each tray 43,79 and 142 days after the start of the target generation. Fifty days after the start of the target generation, as measures of size and spatial spread of clones, we counted on three randomly chosen clones (i.e. the product derived from a single individually planted rosette) in each tray the number of rosettes, and measured the horizontal distance between their two most-distant rosettes. After 148 days, as measures of size, sexual and vegetative reproduction, and growth form of clones, we counted on three randomly chosen clones in each tray the number of rosettes, flowers, rooted rosettes and branches, and measured the length of the longest leaf on the originally planted rosette and the length of the first internode on the longest stolon branch. As measures of sexual and vegetative reproductive allocation, we calculated the proportion of flowering rosettes and of rooted rosettes by dividing the number of flowers and rooted rosettes, respectively, by the total number of rosettes. As measures of growth form, we calculated the spatial spread per rosette and the number of branches per rosette by dividing the spatial spread and number of branches, respectively, by the total number of rosettes.

\section{Analyses}

All variables were analysed with hierarchical analyses of variance using the statistical package SPSS (SPSS Inc., 
Chicago, IL, USA). Selection density and test density were considered as fixed factors and lines within each selection density as random factor. The number of rosettes and rooted roseltes per tray were analysed with repeated-measures analyses of variance. In these analyses, the between-subject effects refer to trays, whereas the within-subject effects refer to census dates. Because Mauchly's tests revealed that there was no compound symmetry of the covariance matrix of the number of rosettes per tray (Mauchly, 1940), we corrected the degrees of freedom according to Greenhouse $\&$ Geisser (1959). The number of rosettes, rooted rosettes and flowers per clone, proportion of rooted rosettes, and spatial spread per rosette were log 10 -transformed prior to analyses to achieve normality and homoscedasticity.

We tested whether differences in the proportion of flowering and of rooted rosettes between the low- and high-density test environment were a consequence of plants being at different positions along the same allometric trajectory [for the proportion of flowering rosettes given as the number of flowers $=\alpha$ (number of rosettes) $)^{\beta}$, or a consequence of being along different allometric trajectories (Weiner, 1988). To this end we regressed the number of flowers, and the number of rooted rosettes on the number of rosettes after $\log 10$ transformation, yielding for the number of flowers

$$
\begin{aligned}
& \log 10 \text { (number of flowers) } \\
& \quad=\log 10(\alpha)+\beta \log 10 \text { (number of rosettes) }
\end{aligned}
$$

To test whether the mean number of flowers and rooted rosettes and their regression slopes (allometric exponents) differed between low- and high-density test environments, we used analyses of variance in which the number of rosettes were included as covariate.

\section{Results}

\section{Density of rosettes and rooted rosettes}

During the first 79 days of the target generation (fourth vegetative offspring generation), densities of rosettes and rooted rosettes increased in both test density treatments as a consequence of vegetative spread of the originally planted rosettes (i.e. clones) of $R$. reptans (Fig. 1; effect of census date in Table 1). Thereafter, the number of rosettes further increased in the low-density test environment and decreased in the high-density test environment (Fig. 1; census date-by-test density interaction in Table 1), indicating mortality of rosettes in the highdensity test environment. The number of rooted rosettes hardly changed after day 79 . During growh of the target generation, there were no significant differences in the actual density of rosettes and rooted rosettes between lines of low and high density (Fig. 1; Table 1). This indicates that differences in clonal life-history traits between plants of the low- and high-density lines

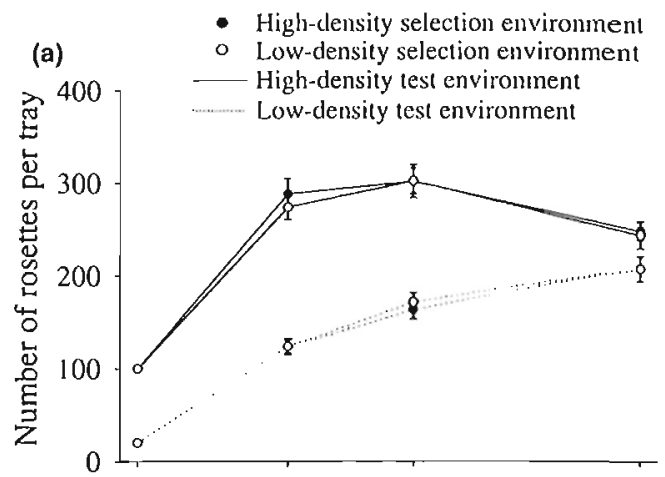

(b)

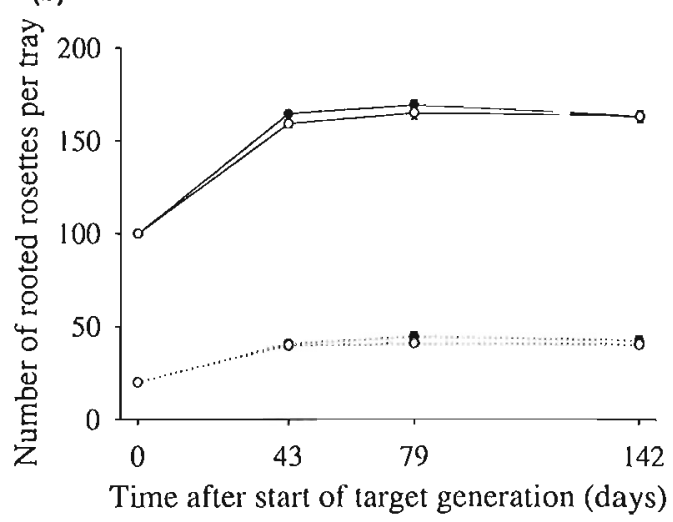

Fig. I Rosetic densities: the effects of selection density of the lines, test density and census date on the mean (a) number of rosettes and (b) number of rooted rosettes per tray of the fourth vegetative offspring generation in the cxperiment with Ranunculus reptans. Measurements were made 43,79 and 142 days after the start of this generation. Parameter estimates are given $\pm 1 \mathrm{SE}$.

reported below cannot be attributed to differences between lines in actual test densities.

\section{Reproductive allocation of clones}

After 148 days in the target generation, the proportions of flowering and of rooted rosettes of clones were 0.137 and 0.496 , respectively (Fig. 2). Plants in the highdensity test environment had a significantly lower proportion of flowering rosettes $(-80.5 \%)$, and a higher proportion of rooted rosettes (184.3\%; Fig. 2; Table 2), indicating a plastic shift from sexual to vegetative reproduction with increasing density.

The allocation coefficient $(\alpha)$ of the log-log regression of the number of flowers was lower for the low-density test environment $(\alpha=0.797)$ than for the high-density test environment $(\alpha=0.966)$, although not significant (test density effect in AnCova: $\left.F_{1.179}=2.38, P=0.125\right)$. The slope $(\beta)$ of this regression, however, was significantly higher for the low-density test environment $(\beta=0.693)$ 
Table 1 Rosette densitics: summary of analyses of variance of effects of selection density of the lines, test density and census date on the number of roscttes, and of rooted rosettes per tray in the fourth vegetative offspring generation in the experiment with Ranunculus replans. We used repeated-measures analyses of variance to study both variation between trays (between subject) and variation within trays (within subject). For the number of rosetics, significance levels of the within-subject effects are corrected by using the Grecnhouse-Geisser (G-G) correction factor $\varepsilon$.

\begin{tabular}{|c|c|c|c|c|c|c|c|c|}
\hline \multirow[b]{2}{*}{ Effect } & \multirow[b]{2}{*}{ d.f. } & \multicolumn{4}{|c|}{ Number of rosettes } & \multicolumn{3}{|c|}{ Number of rooted rosettes } \\
\hline & & MS & $F$ & $P$ & $G-G$ & MS & $F$ & $P$ \\
\hline \multicolumn{9}{|l|}{ Between trays } \\
\hline Selection density & 1 & 349 & 0.04 & 0.843 & - & 415.25 & 0.22 & 0.643 \\
\hline Line (S) & 29 & 8589 & 1.81 & 0.068 & - & 1889.07 & 12.22 & 0.000 \\
\hline Test densily & 1 & 469717 & 99.07 & 0.000 & - & 600802.86 & 3886.79 & 0.000 \\
\hline$S * T$ & 1 & 1561 & 0.33 & 0.571 & - & 105.44 & 0.68 & 0.417 \\
\hline Tray & 25 & 4741 & & & & 154.58 & & \\
\hline \multicolumn{9}{|l|}{ Within trays } \\
\hline Census date & 2 & 14900 & 22.25 & 0.000 & 0.000 & 287.60 & 4.52 & 0.015 \\
\hline $\mathrm{C} \cdot \mathrm{s}$ & 2 & 527 & 0.79 & 0.459 & 0.285 & 16.07 & 0.26 & 0.772 \\
\hline$C ` L(S)$ & 58 & 670 & 0.66 & 0.936 & 0.910 & 62.97 & 1.22 & 0.237 \\
\hline $\mathrm{C}^{\prime} \top^{\top}$ & 2 & 67196 & 66.27 & 0.000 & 0.000 & 92.98 & 1.80 & 0.176 \\
\hline$C^{*} T^{*} S$ & 2 & 56 & 0.06 & 0.946 & 0.908 & 49.77 & 0.96 & 0.390 \\
\hline Error & 50 & 1014 & & & & 51.77 & & \\
\hline
\end{tabular}

than for the high-density test environment $(\beta=0.473$; number of rosettes-by-test density interaction in ANCOVA: $F_{1,179}=15.27, P=0.000$ ). The allocation coefficient of the log-log regression of the number of rooted rosertes was also lower for the low-density test environment $(\alpha=0.863)$ than for the high-density test environment $(\alpha=1.015)$, although not significant (test density effect in ANCOVA: $\left.F_{1.179}=2.72, P=0.101\right)$. The slope of this regression, however, was significantly higher for the low-density test environment $(\beta=0.195)$ than for the high-density test environment $(\beta=0.114$; number of rosettes-by-test density interaction in ANCova: $\left.F_{1.179}=11.61, P=0.001\right)$. These results indicate that if the allometric relations within the low-and high-density test environments hold within each other data ranges after extrapolation, the proportion of flowering rosettes would still have been higher in the low-density test environment if plants would have grown larger but that the proportion of rooted rosettes would have been higher in the lowdensity test environment than in the high-density test environment. Therefore, these allometric relations suggest that the plastic shift from sexual to vegetative reproduction with increasing density would still have been apparent but less pronounced if plants would have grown larger.

There were no significant differences in the proportion of flowering rosettes and of rooted rosettes between plants of low- and high-density lines (Fig. 2; Table 2). This indicates that reproductive allocation is plastic but did not respond to density-dependent selection.

\section{Growth form of clones}

After 50 days in the target generation, the spatial spread per rosette was on average $3.4 \mathrm{~mm}$ (Fig. 3a). After
148 days, the length of the longest leaf on the originally planted rosettes was on average $39.5 \mathrm{~mm}$, the average number of stolon branches per rosette was 0.16 , and the length of the first internode on the longest stolon branch was $38.1 \mathrm{~mm}$ (Fig. 3b-d).

Plants in the high-density test environment had a significantly lower spatial spread per rosette $(-83.9 \%)$, shorter leaves $(-15.1 \%)$, and fewer stolon branches per rosette $(-61.8 \%)$ with shorter internodes $(-13.5 \%)$ than those growing in the low-density test environment (Fig. 3; Table 3), indicating plasticity in these growth form characteristics.

The spatial spread per rosette did not differ significantly between plants of the low- and high-density lines (Fig. 3a; Table 3). Plants of high-density lines, however, tended to have longer leaves $(6.1 \%)$ than those of lowdensity lines $(P=0.105$; Fig. 3b; Table 3). Moreover, when grown in the high-density test environment, plants of high-density lines had fewer stolon branches per rosette $(-33.7 \%)$ with slightly shorter internodes $(-2.7 \%)$ than those of low-density lines, whereas in the low-density test environment, they had more stolon branches per rosette $(37.3 \%)$ with longer internodes (7.0\%; Fig. 3c,d). The selection density-by-test density interaction was significant for the number of stolon branches per rosette and marginally significanı for internode length (Table 3). These results indicate that plants of high-density lines had a more plastic growth form than those of low-density lines. Because of these differences in plasticity, and because a high branching frequency was correlated with long internodes, lines could not be clearly classified as having a guerrilla or phalanx strategy. 

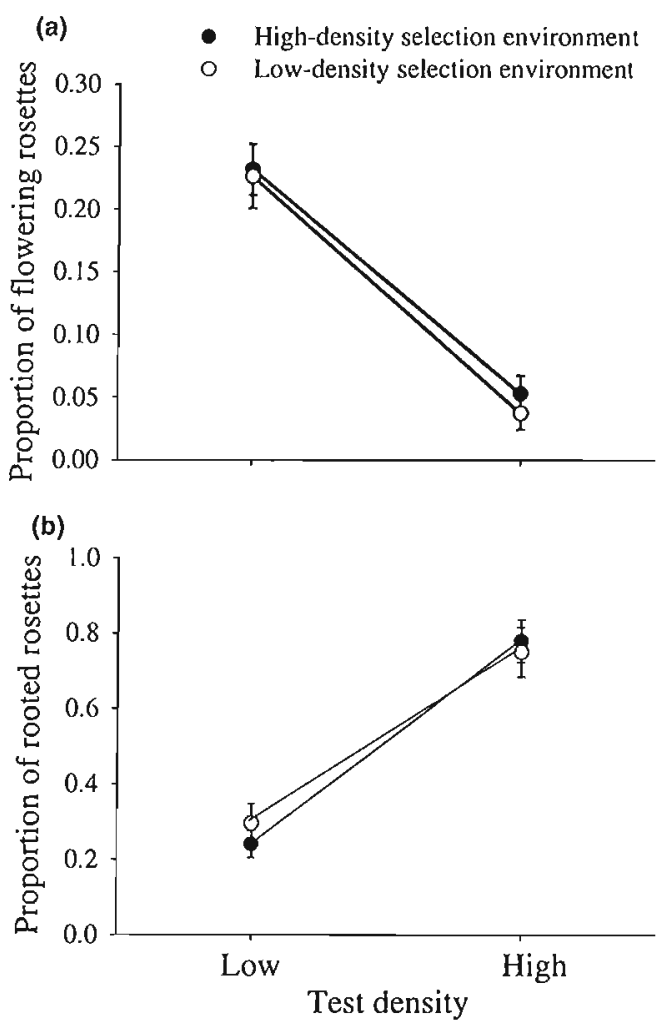

Fig. 2 Reproductive allocation: the effects of selection density of lines, test density and census date on (a) proportion of flowering rosettes, (b) proportion of rooted rosettes of plants by day 148 of the fourth vegetative offspring generation in the experiment with Ranunculus reptans. Parameter estimates are given $\pm 1 \mathrm{SE}$

\section{Size and reproduction of clones}

After 148 days in the target generation, plants had on average 3.0 rosettes of which 1.1 were rooted and 0.8 bore a flower (Fig. 4). Plants growing in the high-density test environment had significantly fewer rosettes $(-75.0 \%)$, rooted rosettes $(-15.8 \%)$ and flowers
$(-90.4 \%)$ than those growing under low density (Fig. 4; Table 4), indicating significant plastic changes in these fitness characteristics.

In the low-density test environment, plants of highdensity lines had more rosettes $(28.9 \%)$, rooted rosettes $(15.0 \%)$ and flowers $(16.0 \%)$ than plants of low-density lines (Fig. 4). These differences between low- and highdensity lines were not apparent in the high-density test environment (Fig. 4). This was reflected in a marginally significant selection density-by-test density interaction for the number of rooted rosettes (Table 4). The selection density effect, however, was not significant for any of these traits (Table 4). These results suggest genetic dillerentiation between low- and high-density lines in plasticity of fitness characteristics.

\section{Discussion}

\section{Plastic responses to test densities}

The response of all studied traits to test density demonstrates pronounced phenotypic plasticity of the clonal life history of $R$. reptans. The observed plastic shift from sexual to vegetative reproduction with increasing density might be beneficial as it increases the competitive strength of plants (Loehle, 1987). However, although there is no congruent clonal plant life history theory, most studies predict that it would be adaptive to shift from vegetative to sexual reproduction with increasing density because seed dispersal may act as an escape mechanism from the unfavourable high-density environment (Ogden, 1974; Abrahamson, 1975, 1980; Williams, 1975; Loehle, 1987; Gardner \& Mangel, 1999). In a previous study with $R$. reptans we found such a predicted response (van Kleunen et al., 2001). There, clones grew much larger than the ones in the current study within the same time period, most likely because of higher nutrient availability. Allometric relations of sexual and vegetative reproduction with size indicated that when plants in the current study would have grown larger, they would have had a higher proportion of rooted rosettes although also still a higher proportion of flowering rosettes under low density

Table 2 Reproductive allocation: summary of analyses of variance of effects of selection density of the lines and test density on the proportion of flowering roseties, and of rooted rosettes by day 148 of clones of the fourth vegetative offspring generation in the experiment with Ranunculus replans.

\begin{tabular}{|c|c|c|c|c|c|c|c|}
\hline \multirow[b]{2}{*}{ EHect } & \multirow[b]{2}{*}{ d.l. } & \multicolumn{3}{|c|}{ Proportion of flowering rosettes roseltes } & \multicolumn{3}{|c|}{ Proportion of rooted rosettes } \\
\hline & & MS & $F$ & $P$ & MS & $F$ & $P$ \\
\hline Selection density & 1 & 0.01268 & 0.82 & 0.372 & 0.00504 & 0.45 & 0.508 \\
\hline Line (S) & 29 & 0.01543 & 0.80 & 0.728 & 0.01122 & 0.96 & 0.545 \\
\hline Test density & 1 & 1.46200 & 75.32 & 0.000 & 0.86100 & 73.63 & 0.000 \\
\hline$S^{*} T$ & 1 & 0.00049 & 0.03 & 0.875 & 0.00951 & 0.81 & 0.375 \\
\hline Tray $(S, L, T)$ & 27 & 0.01941 & 1.51 & 0.068 & 0.01170 & 1.88 & 0.011 \\
\hline Error & 120 & 0.01284 & & & 0.00622 & & \\
\hline
\end{tabular}


(a)

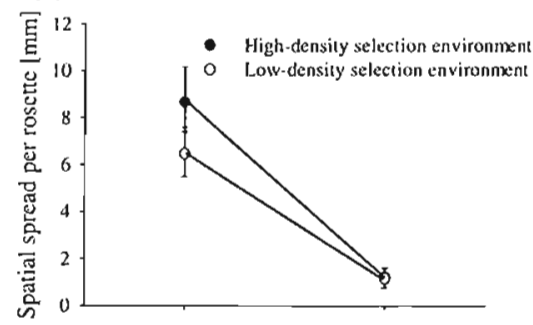

(c)

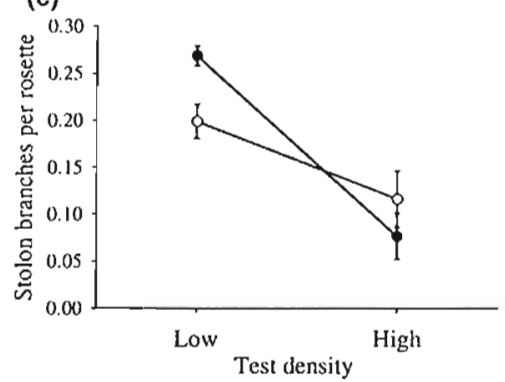

(b)
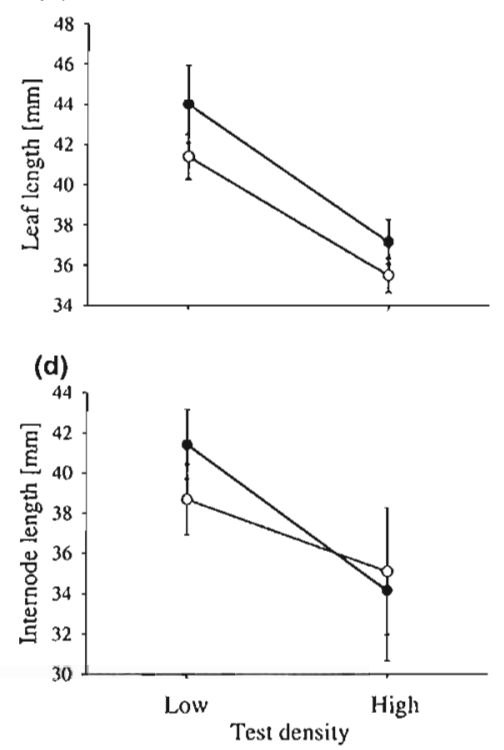

Fig. 3 Growth form: the effects of selection density of lines and test-density treatment on (a) the spatial spread per rosette by day 50 and (b) length of the longest leaf of the originally planted roseuc, (c) number of stolon branches per rosette and (d) length of the first internode on the longest stolon branch by day 148 of the fourth vegetative offspring generation in the experiment with Ranunculus reptans. Parameter estimates are given \pm 1 SE.

Table 3 Growth form: summary of analyses of variance of effects of selection density of the lines and test density on spatial spread per rosette by day 50, and length of the longest leaf on the originally planted rosette, number of branches per rosette and length of the first internode on the longest stolon branch by day 148 of clones of the fourth vegetative offspring generation in the experiment with Ranunculus replans.

\begin{tabular}{|c|c|c|c|c|c|c|c|c|c|c|c|c|c|}
\hline \multirow[b]{2}{*}{ Effect } & \multirow[b]{2}{*}{ d.t. } & \multicolumn{3}{|c|}{ Spatial spread per rosette } & \multicolumn{3}{|c|}{ Length of longest leaf } & \multicolumn{3}{|c|}{$\begin{array}{l}\text { Number of branches } \\
\text { per roselle }\end{array}$} & \multicolumn{3}{|c|}{ Length of first internode } \\
\hline & & MS & $F$ & $P$ & MS & $F$ & $P$ & MS & $F$ & $P$ & MS & $F$ & $P$ \\
\hline Selection density & 1 & 0.138 & 0.49 & 0.489 & 249.57 & 2.80 & 0.105 & 0.01747 & 0.70 & 0.409 & 79.469 & 0.50 & 0.485 \\
\hline Line (S) & 29 & 0.281 & 1.88 & 0.049 & 89.01 & 1.34 & 0.223 & 0.02495 & 1.15 & 0.359 & 158.404 & 3.69 & 0.005 \\
\hline Test density & 1 & 15.311 & 102.47 & 0.000 & 1725.89 & 25.99 & 0.000 & 0.74900 & 34.55 & 0.000 & 340.669 & 7.93 & 0.013 \\
\hline$S \cdot T$ & 1 & 0.127 & 0.85 & 0.365 & 12.66 & 0.19 & 0.666 & 0.14800 & 6.84 & 0.014 & 186.006 & 4.33 & 0.055 \\
\hline $\operatorname{Tray}(S, L, D)$ & 27 & 0.149 & 0.67 & 0.894 & 66.40 & 1.21 & 0.243 & 0.02169 & 1.17 & & 42.977 & 0.46 & \\
\hline Error & 120 & 0.225 & & & 55.04 & & & 0.01851 & & & 92.952 & & \\
\hline
\end{tabular}

*d.f. of tray and error is 28 and 122, respectively, for the spatial spread per rosette.

†d.f. of line, tray and error is 28,15 and 57 , respectively. for the length of the first internode.

than under high density. Therefore, the discrepancy between both studies is not likely to be a consequence of plants being at different positions along their allometric trajectories for sexual and vegetative reproduction. According to a study on Abutilon theophrasti the effect of density on reproductive allocation can depend on nutrient availability (Sugiyama 8 Bazzaz, 1997). Therefore, a possible explanation for the different plastic responses in reproductive allocation between both studies could be the interaction of different nutrient availability with the effect of ramet density on reproductive allocation.

Growth form plasticity might allow to avoid local high densities. The reduced branching frequency in the highdensity test environment is likely to result in more linear growth of stolon branches and may thus enhance the chance to escape from local high-density conditions. However, the shorter internodes and resulting lower spatial spread per rosette reduce this beneficial effect. The shorter internodes and shorter leaves at high density are most likely caused by overall reduced rosette sizes at high density as a consequence of resource limitation, and suggest reduced local foraging ability for light both in the vertical and horizontal plane (van Kleunen $\&$ Fischer, 2001).

\section{Responses to selection}

The growth form of $R$. replans responded to densitydependent selection in our clonally propagated lines. Independent of the test density, plants of the highdensity lines tended to have longer leaves than plants of the low-density lines, which may allow them to capture more light under high-density conditions (Schmitt $\&$ Wulff, 1993). Other selection responses of growth form 

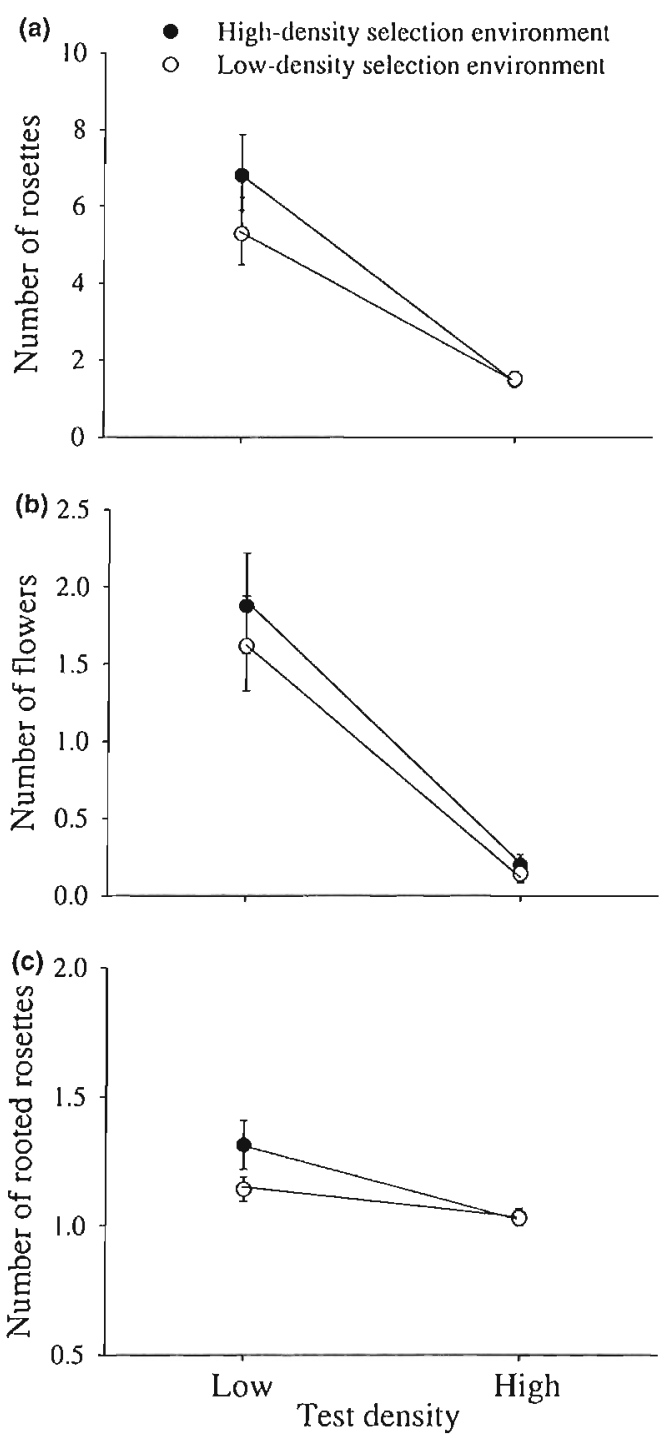

Fig. 4 Size and reproduction of clones: the effects of selcction density of the lines, test density and census date on (a) number of rosettes, (b) number of flowers and (c) number of rooted rosettes of plants by day 148 of the fourth vegetative offspring generation in the experiment with Ranunculus repians. Parameter estimates are given \pm 1 SE.

were not consistent over the two test densities, because plants of high-density lines had a more plastic growth form than those of low-density lines. When grown in the high-density test environment, plants of high-density lines had fewer branches per rosette with slightly shorter internodes than those of low-density lines (Figs $3 \mathrm{c}, \mathrm{d}$ ). This is supported by another density-dependent selection experiment with $R$. reptans, in which subsequen offspring generations were started from seeds instead of vegetative offspring, where plant of high-density lines also had a significantly lower branching frequency (M. van Kleunen, M. Fischer \& B. Schmid, unpublished data). On the other hand, in the current experiment, plants of the high-density lines had more branches per rosette with longer internodes when grown in the lowdensity test environment. This higher plasticity of high. density lines indicates that plasticity can evolve as a correlated trait to selection in a single environment. According to the Jinks-Connoly rule (Falconer, 1990). traits selected synergistically (i.e. selected in the direction stimulated by the environment) should be more plastic than traits selected antagonistically (i.e. selected against the direction stimulated by the environment). Therefore, plasticity in branching frequency could have evolved as a correlated trait when the high-density environment selected for a low branching frequency whereas this trait was selectively neutral in the low-density environment.

We started each selection line with 40 genotypes from 10 diflerent populations around Lake Constance. Therefore, each line represents the metapopulation at Lake Constance, and as a consequence, the results apply to the metapopulation level. However, because there is generally considerable variation among genotypes within populations (Fischer et al., 2000a; Prati \& Schmid, 2000; van Kleunen et al., 2000a,b; van Kleunen 8 Fischer, 2001), it is likely that our study also illustrates the potential for evolution within single natural populations of $R$. reptans.

The importance of intergenotype selection has been shown in multigeneration experiments with bacteria (e.g. Leroi et al., 1994). The observed responses to selection in our study, however, indicate changes in genet composition and frequency within populations of clonal plants may occur already after a few generations of clonal reproduction. This has also been confirmed by Solbrig \& Simpson (1977) who found large changes in the lrequency of two apomictic biotypes of Taraxacum officinale after 4 years of growth under different levels of disturbance. Although in exclusively clonally propagating organisms, genetic variation may be quickly depleted because of the absence of recombination, the initial response to selection may be rapid because clonal offspring do not only inherit additive effects of alleles but also the nonadditive effects (i.e. effects of dominance and epistatic interactions; Pan \& Price, 2001). Because the largest genets are also likely to produce most sexual oflspring (van Kleunen et al., 2002). Changes in genet composition and frequency will also alfect subsequent evolutionary change over sexual genel generations, at least to the degree that observed selection responses are additive

\section{Adaptivity of clonal life history traits}

If the observed plastic response in reproductive allocation is adaptive, selection pressures should consistently have 
Table 4 Size and reproduction of clones: summary of analyses of variance of effects of selection density of the lines, test density and census date on the number of rosettes, of flowers, and of rooted roseltes by day 148 of clones of the fourth vegetative offspring generation in the experiment with Ranunculus reptans.

\begin{tabular}{|c|c|c|c|c|c|c|c|c|c|c|}
\hline \multirow[b]{2}{*}{ Effect } & \multirow[b]{2}{*}{ d.f. } & \multicolumn{3}{|c|}{ Number of rosettes } & \multicolumn{3}{|c|}{ Number of flowers } & \multicolumn{3}{|c|}{ Number of rooted rosettes } \\
\hline & & MS & $F$ & $P$ & MS & $F$ & $P$ & MS & $F$ & $P$ \\
\hline Selection density & 1 & 0.214 & 1.39 & 0.248 & 0.08513 & 1.44 & 0.240 & 0.05126 & 2.38 & 0.134 \\
\hline Line (S) & 29 & 0.154 & 0.85 & 0.672 & 0.05928 & 0.75 & 0.777 & 0.02155 & 1.74 & 0.077 \\
\hline Test density & 1 & 15.722 & 86.30 & 0.000 & 6.05700 & 76.55 & 0.000 & 0.25800 & 20.77 & 0.000 \\
\hline$S^{*} T$ & 1 & 0.236 & 1.30 & 0.265 & 0.01312 & 0.17 & 0.687 & 0.05053 & 4.07 & 0.054 \\
\hline Tray $(S, L, D)$ & 27 & 0.182 & 1.80 & 0.017 & 0.07918 & 1.66 & 0.033 & 0.01241 & 0.63 & 0.921 \\
\hline Error & 120 & 0.101 & & & 0.04758 & & & 0.01987 & & \\
\hline
\end{tabular}

favoured plants with a high sexual reproductive allocation under low density and the ones with a high vegetative reproductive allocation under high density. The absence of a difference in reproductive allocation between the low- and high-density lines, therefore migh suggest that the observed plasticity in reproductive allocation does not constitute an adaptive response. The absence of a response in reproductive allocation to the selection densities might also have been due to genetic correlations with other important life history traits such as the growth form in $R$. reptans (van Kleunen et al., 2002; M. Fischer, M. van Kleunen $\delta$ B. Schmid, unpublished results). However, a more likely explanation for the absence of a response in reproductive allocation to density-dependent selection is that in both density environments, genotypes with a high production of vegetative offspring were favoured because subsequent generations in our experiment were solely lounded from vegetatively produced offspring. Similarly, in another experiment in which we had grown lines under low and high density for three sexually propagated genet generations (i.e. each consecutive generation was founded from sexually produced offspring), there was no difference in reproductive allocation between the low- and highdensity lines (M. van Kleunen, M. Fischer \& B. Schmid, unpublished results). A simulation study of Sackville Hamilton et al. (1987), however, predicted that if genet generations are overlapping (i.e. when there is both sexual and vegetative recruitment) and if the environment changes rapidly, high density may select for an increased allocation to sexual reproduction. This suggests, that in natural populations of $R$. reptans along dynamic shores of lakes and rivers, variation in density may be responsible for the maintenance of genetic variation in reproductive allocation.

Leaf and internode elongation are generally regarded as adaptive plastic responses to shading under high density (Schmitt 8 . Wulff, 1993; Schmitt et al., 1995; van Kleunen $\delta$ Fischer, 2001). This is also suggested by the apparent selection for longer leaves found in the highdensity lines. It might be that in our experiment, the shade signal under high density was too small to induce an active plastic elongation of leaves because, as a consequence of the artificial light in the plant room, both the low and high density test environment had a relatively low light intensity. Therefore, the observed plastic reductions in leaf and internode lengths are likely to be passive responses as a consequence of resource limitation under high density rather than adaptive responses (Leeflang et al., 1998; van Kleunen et al., 2000a).

The fact that plants of high-density lines also had a lower branching frequency when growing in the highdensity test environment than plants of the low-density lines, indicates that the observed plastic reduction in branching frequency is adaptive. The reduced branching frequency in the high-density test environment is likely to result in more linear growth of stolon branches and thus to enhance the chance to escape from local highdensity conditions. In this experiment, however, escape from the high-density environment was not possible, at least not in the horizontal plane. The reduced spatial spread per rosette, however, suggests that stolon growth was in the vertical plane rather than in the horizontal plane. Vertical growth of stolon branches was also found in response to compctition with a naturally co-occurring grass species (van Kleunen $\delta$ Fischer, 2001), and may be more beneficial than horizontal growth because the light gradient is more predictable in the vertical plane (Huber et al., 1998).

Plants of the high-density lines tended to produce more rosettes, rooted rosettes and flowers than plants of the low-density lines when grown in the low-density test environment but not in the high-density test environment. Although the observed differences in fitness characteristics and their plasticities between low- and high-density lines did not meet 'home-away' expectations of local adaptation (Schmid, 1985; van Tienderen, 1992), suggesting that the observed differences between low- and high-density lines do not constitute adaptations to the low- and high-density test environments, the results show that fitness characteristics and their plasticities may evolve. Because we had a large number of replicate lines in this experiment, it is unlikely that differences between the low- and high-density lines are a consequence of random genetic drift (Falconer $\delta$ 
Mackay, 1996). Possibly the high test density was quite stressful for plants of both low- and high-density lines, and therefore differences between lines only become apparent in the more benign low-density environment. Another explanation could be that the test environments slightly differed from the ones in the previous generations. However, although we used smaller trays in the target generation than in the previous generations, soil mixture and rosette densities were similar. The smaller size of clones in the target generation in comparison with the size in the first generation (see van Kleunen et al., $2001)$ suggests that there were less nutrients available for the plants of the target generation. Therefore, nutrient availability in the low-density environment of the target generation may have been more similar to the nutrient availability under high density in the previous generations. As a consequence, the selective effect of high density may have become only apparent in the lowdensity test environment.

\section{Conclusions}

We conclude that the clonal life history traits reproductive allocation and growth form of $R$. reptans show strong plastic responses to density. Moreover, after four generations of clonal propagation, plants of high-density lines tended to have longer leaves, and have a more plastic growth form than plants of low-density lines. The response to density-dependent selection pointed in the same direction as the plastic response to density for the branching frequency but not for leaf length, indicating that plasticity in branching frequency is adaptive whereas the one in leaf length is not. Because in its natural habitat $R$. reptans sometimes reproduces exclusively vegetatively and grows under varying ramet densities, the results of this study indicate that densitydependent intergenotype selection is important in the clonal life-history evolution of $R$. reptans.

\section{Acknowledgments}

We thank Kati Dräger, Gillian Rutherlord-Rauh, Rahel Schmid, Franz Fritsche, Philipp Kocyan and Thomas Pfluger for practical assistance, and Bernhard Schmid for stimulating discussions. We acknowledge financial support by the Swiss National Science Foundation (Grant $31-49728.96)$.

\section{References}

Abrahamson, W.G. 1975. Reproductive strategies in dewberries. Ecology 56: 721-726.

Abrahamson, W.G. 1980. Demography and vegetative reproduction. In: Demography and Evolution in Planl Populations (O. T. Solbrig ed.), pp. 89-106. Blackwell Scientific Publications, Oxford.
Bell, A.D. 1984. Dynamic morphology: a contribution to plant population ecology. In: Perspectives on Plant Population Ecology (R. Dirzo \& J. Sarukhan, eds), pp. 48-65. Sinauer, Sunderland. Bradshaw, A.D. 1965. Evolutionary significance of phenotypic plasticity in plants. Adv. Genet. 13: 115-155.

Donohue, K., Messiqua, D., Pyle, E.H., Heschel, M.S. \& Schmit, J. 2001. Evidence of adaptive divergence in plasticity: densityand site-dependent selection on shade-avoidance responses in Impatiens capensis. Evolution 55: 1956-1968.

Eckert, C.G. 2001. The loss of sex in clonal plants. Evol. Ecol. 15 501-520.

Falconer, D.S. 1990. Selection in different environments: effects on environmental sensitivity (reaction norm) and on mean performance. Genet. Res. 56: 57-70.

Falconer, D.S. \& Mackay T.F.C. 1996. Introduction to Quantitative Genetics. Longman, Essex.

Fischer, M. \& van Kleunen, M. 2001. On the evolution of clonal plant life histories. Evol. Ecol. 15: 565-582.

Fischer, M., van Kleunen, M. \& Schmid, B. 2000a. Genetic Allee effects on performance, plasticity and developmental stability in a clonal plant. Ecol. Lell. 3: 530-539.

Fischer, M., Husi, R., Prati, D., Peintinger, M., van Kleunen, M. \& Schmid, B. 2000b. RAPD variation among and within small and large populations of the rare clonal plant Ranunculus reptans (Ranunculaceae). Am. J. Bot. 87: 1128-1137.

Gardner, S.N. \& Mangel, M. 1999. Modeling investments in seeds, clonal offspring, and translocation in a clonal plane. Ecology 80: 1202-1220.

Greenhouse, S.W. \& Geisser, S. 1959. On methods in the analysis of profile data. Psychometri 24: 95-112.

Harper, J.L. 1981. The concept of populations in modular organisms. In: Theoretical Ecology: Principles and Applications (R M. May, ed.), pp. 53-77. Blackwell Scientific Publications, Oxford.

Hess, H.E., Landolt, E. E Hirzel. R. 1980. Flora der Schweiz, Vol. 2. Birkhäuser, Basel.

Huber, H., Fijan, A. G During, H.J. 1998. A comparative study on spacer plasticity in erect and stoloniferous herbs. Oikos 81: 576-586.

Humphrey, L.D. \& Pyke, D.A. 1998. Demographic and growth responses of a guerrilia and a phalanx perennial grass in competitive mixtures. J. Ecol. 86: 854-865.

van Kleunen, M. \& Fischer, M. 2001. Adaptive evolution of plastic foraging responses in a clonal plant. Ecology 82: 3309 3319.

van Kleunen, M., Fischer, M. \& Schmid, B. 2000a. Clonal integration in Ranunculus replans: by-product or adaptation? J. Evol. Biol. 13: 237-248.

van Kleunen, M., Fischer, M. \& Schmid, B. 2000b. Costs of plasticity in foraging characteristics of the clonal plant Ranunculus reptans. Evolution 54: 1947-1955.

van Kleunen, M., Fischer, M. \& Schmid, B. 2001. Effects of intraspecific competition on size variation and reproductive allocation in a clonal plant. Oikos 94: 515-524.

van Kleunen, M., Fischer, M. \& Schmid, B. 2002. Experimental life-history evolution: selection on the allocation to sexual reproduction and its plasticity in a clonal plant. Evolution 56 : 2168-2177.

Klimeš, L., Klimešová, J., Hendriks, R. E van Groenendael, J. 1997. Clonal plant architecure: a comparative analysis of form and function. In: The Ecology and Evolution of Clonal Plants 
(H. de Kroon \& J. van Groenendael, eds), pp. 1-30. Backhuys Publishers, Leiden.

Leeflang, L., During, H.J. \& Werger, M.J.A. 1998. The role of petioles in light acquisition by Hydrocotyle vulgaris $\mathrm{L}$. in a vertical light gradient. Oecologia 117: 235-238.

Leroi, A.M., Lenski, R.E. \& Bennet, A.F. 1994. Evolutionary adaptation to temperature. III. Adaptation of Escherichia coli to a temporally varying environment. Evolution 48: 1222-1229.

Lively, C.M. 1999. Developmental strategies in spatially variable environments: barnacle shell dimorphism and strategic models of selection. In: The Ecology and Evolution of Inducible Defenses (R. Tollrian \& C.D. Harvell, eds), pp. 215-258. Princetol University Press, Princeton.

Loehle, C. 1987. Partitioning of reproductive effort in clonal plants: a benefit-cost model. Oikos 49: 199-208.

Lovett Doust, L. 1981. Population dynamics and local specialization in a clonal plant (Ranunculus repens). I. The dynamics of ramets in contrasting habilats. J. Ecol. 69: 743-755.

MacArthur, R.IH. \& Wilson, E.O. 1967. The Theory of Island Biogeography. Monographs in Population Biology 1. Princeton University Press, Princeton.

Mauchly, J.W. 1940. Signilicance test for sphericity of a normal n-variate distribution. Ann. Math. Stat. 29: 204-209.

Mueller, L.D. 1997. Theoretical and empirical examination of density-dependent selection. Ann. Rev. Ecol. Syst. 28: 269-288.

Ogden, J. 1974. The reproductive strategy of higher plants: II. The reproductive strategy of Tussilago farfara L. J. Ecol. 62: 291 324.

Pan, J.J. \& Price, J.S. 2001. Fitness and evolution in clonal plants: the impact of clonal growth. Evol. Ecol. 15: 583-600.

Pianka, E.R. 1970. On $\mathrm{r}$ and K selection. Am. Nat. 104: 592-597.

Prati, D. \& Peintinger, M. 2000. Biological flora of Central Europe: Ranunculus reptans L. Flora 195: 135-145.

Prati, D. \& Schmid, B. 2000. Genetic differentiation of lifehistory traits within populations of the clonal plant Ranunculus reptans. Oikos 90: 442-456.

Sackville Hamilton, N.R., Schmid, B. \& Harper, J.L. 1987. Lifehistory concepts and the population biology of clonal organisms. Proc. R. Soc. Lon. 232: 35-57.

Salisbury, E.J. 1942. The Reproductive Capacity of Plants: Studies in Quantitative Biology. G. Bell and Sons, London.

Scheiner, S.M. \& Callahan, H.S. 1999. Measuring natural selection on phenotypic plasticity. Evolution 53: 1704-1713.

Schmid, B. 1985. Clonal growth in grassland perennials III. Genetic variation and plasticity between and within populations of Bellis perennis and Prunella vulgaris. J. Ecol. 73: 819830.
Schmid, B. \& Harper, J.L. 1985. Clonal growth in grassland perennials. I. Density and pattern-dependent competition between plants with different growth forms. J. Ecol. 73: 793808.

Schmitt, J., Dudley, S.A. \& Pigliucci, M. 1999. Manipulative approaches to testing adaptive plasticity: phytochromemediated shade-avoidance responses in plants. Am. Nat. 154 S43-S54.

Schmitt, J., McCormac, A.C. \& Smith, H. 1995. A test of the adaptive plasticity hypothesis using transgenic and mutant plants disabled in phytochrome-mediated elongation responses to neighbors. Am. Nat. 146: 937-953.

Schmitt, J. \& Wulff, R.D. 1993. Light spectral quality, phy10chrome and plant competition. Trends Ecol. Evol. 8: 47-51.

Solbrig, O.T. \& Simpson, B.B. 1977. A garden experiment on competition between biotypes of the common dandelion (Taraxacum officinale). J. Ecol. 65: 427-430.

Sugiyama, S. \& Bazzaz, F.A. 1997. Plasticity of seed output in response to soil nutrients and density in Abutilon theophrasti implications for maintenance of genetic variation. Oecologia 112: $35-41$.

Sultan, S.E. 1992. Phenotypic plasticity and the Neo-Darwinian legacy. Evol. Trends Plants 6: 61-71.

van Tienderen, P.H. 1992. Variation in a population of Plantago lanceolata along a topographical gradient. Oikos 64: 560-572.

Van Buskirk, J. \& Relyea, R.A. 1998. Selection for phenotypic plasticity in Rana sylvatica tadpoles. Biol. J. Linn. Soc. 65: 301328.

Weiner, J. 1988. The influence of competition on plant reproduction. In: Plant Reproductive Ecology (J. Lovett Doust \& L. Lovelı Doust, eds), pp. 228-245. Oxford University Press, New York.

Weinig, C. 2000. Differing selection in alternative competitive environments: shade-avoidance responses and germination timing. Evolution 54: 124-136.

Williams, G.C. 1975. Sex and Evolution. Princeton University Press, N.J, USA.

Winkler, E., Fischer, M. \& Schmid, B. 1999. Modelling the competitiveness of clonal plants by complementary analytical and simulation approaches. Oikos 85: 217-233.

Winkler, E. \& Schmid, B. 1995. Clonal strategies of herbaceous plant species: a simulation study on population growth and competition. Abstr. Bot. 19: 17-28. 